\title{
Correction to: Integrating MCDM and GIS for renewable energy spatial models: assessing the individual and combined potential for wind, solar and biomass energy in Southern Spain
}

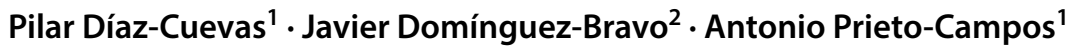

Published online: 23 October 2019

๑) Springer-Verlag GmbH Germany, part of Springer Nature 2019

\section{Correction to: Clean Technologies and Environmental Policy https://doi.org/10.1007/s10098-019-01754-5}

In the original article by Díaz et al. (2019), the authors have become aware of an error in the application of Equation 4, aimed at checking the validity of the method.

As it appears in the article,

$\mathrm{Cr}=\frac{\mathrm{Ci}}{\mathrm{Ri}}=\frac{0.076}{0.9}=0.08 \quad \mathrm{Ci}=\frac{(4.022-4)}{(4-1)}=0.0076$

When redoing the calculations, the result is:

$\mathrm{Cr}=\frac{\mathrm{Ci}}{\mathrm{Ri}}=\frac{0.0073}{0.9}=0.008 \quad \mathrm{Ci}=\frac{(4.022-4)}{(4-1)}=0.0073$

The original article can be found online at https://doi.org/10.1007/ s10098-019-01754-5.

Pilar Díaz-Cuevas

pilard@us.es

Javier Domínguez-Bravo

javier.dominguez@ciemat.es

Antonio Prieto-Campos

pcampos@us.es

1 Department of Physical Geography and Regional Geographical Analysis, University of Seville, Seville, Spain

2 Centro de Investigaciones Energéticas, Medioambientales y Tecnológicas, Madrid, Spain
According to this, for the method to be valid, the value of Cr must be less than 0.10. In fact, the value of $\mathrm{Cr}$ is 0.008 , less than 0.10 . Therefore, this change does not affect the results and conclusions obtained.

Publisher's Note Springer Nature remains neutral with regard to jurisdictional claims in published maps and institutional affiliations. 